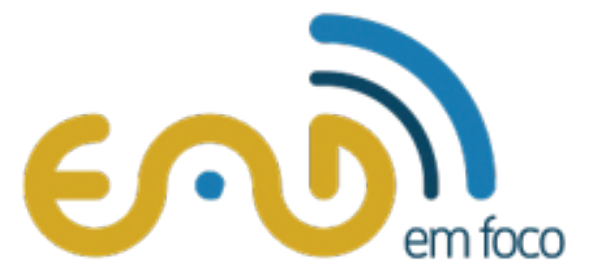

Revista Científica em Educaçăo a Distância

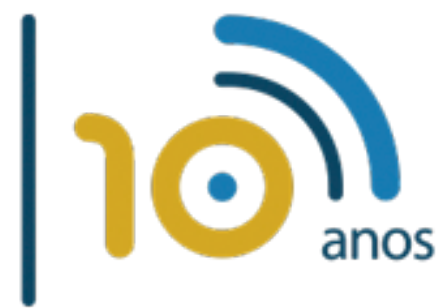

\title{
A Percepção Sobre o E-learning em Períodos de Suspensão das Atividades Organizacionais e de Distanciamento Social
}

Perception About E-learning in Periods of Suspension from Organizational Activities and Social Distance

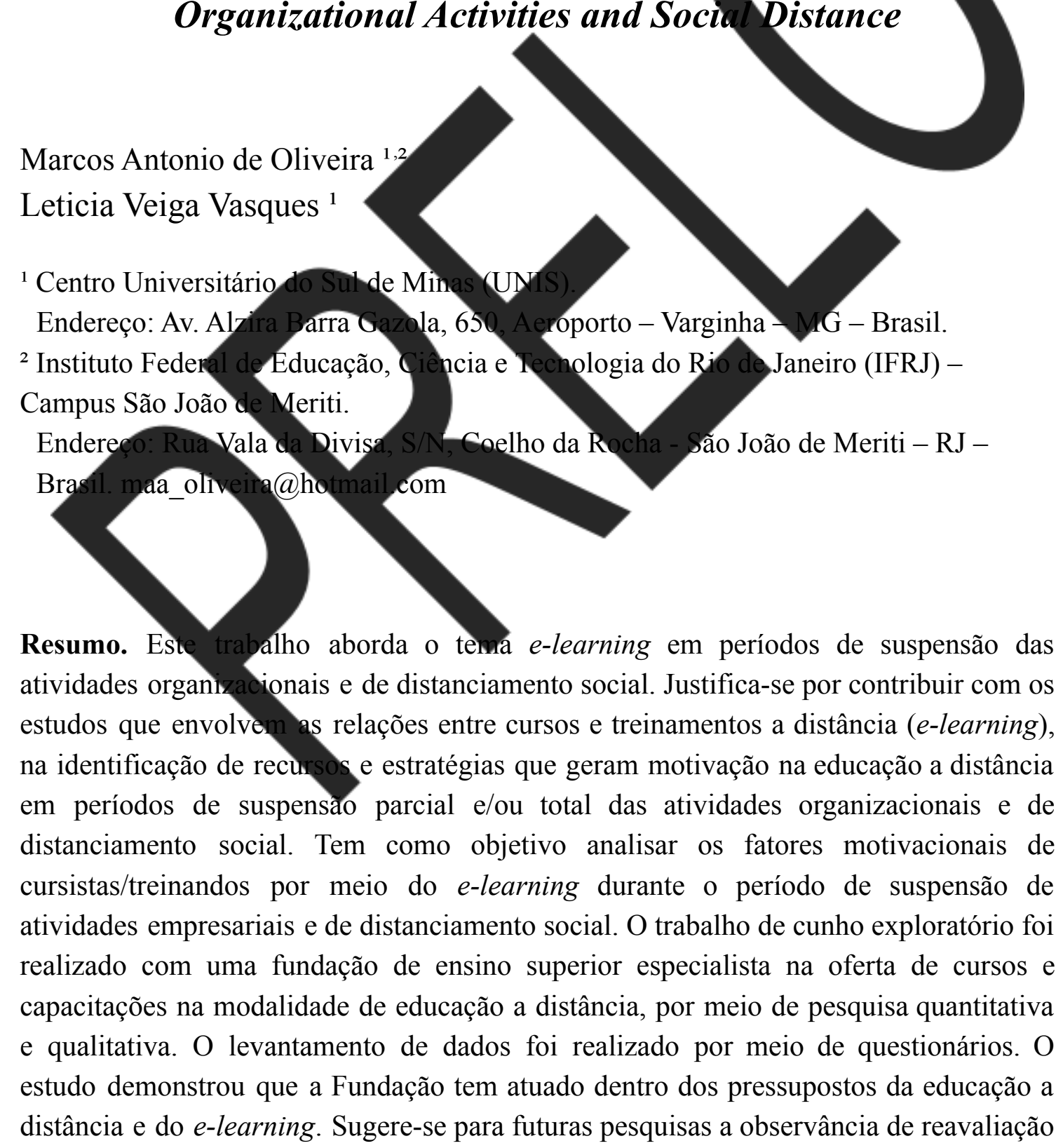


da pertinência ou não de determinados itens do questionário e aplicação de uma pesquisa de campo por meio de empresas que atuam ativamente com programas de e-learning, de maneira que contribua para o desenvolvimento e qualidade da educação a distância.

Palavras-Chave: E-learning. Treinamento-desenvolvimento. Motivação.

Abstract. This work addresses the issue related to the perception of e-learning in periods of suspension from organizational activities and social distance. It is justified by contributing to studies involving the relationships between distance courses and training (e-learning), in the identification of resources and strategies that generate motivation in distance education in periods of partial and/or total suspension of organizational activities and social distance. Aims to analyze the motivational factors of course participants/trainees through the learning technique during the period of suspension of business activities and social distance. The exploratory work was carrjed out with a higher education foundation speciatized in offering courses and training in the modality of distance education, through quantitutive and qualitative research. Data collection was carried out through questionnaires. The study showed that the Foundation, has acted within the assumptions of distance education and e-learning. It is suggested for future pesearch the observance of reassessment of the pertinence or not of certain items of the questionnaire and application of field research through companies, that actively act in e-learning programs, in a way that contributes to the development
and quality of distance education. and quality of distance education. Keyvords. E-learning. Tra
Recebido: $18 / 05 / 2021 \mathrm{~A}$

1. Introdução

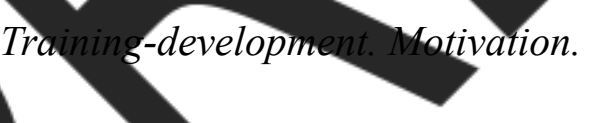

O mundo vem passando por diversas situações que afetam diretamente a vida das pessoas e das organızções; desde início do ano de 2020 até então, a sociedade vem sofrendo com a crise da pandemia, em consequência do Covid-19. Sabe-se que em momentos como esse é preciso que todos os envolvidos busquem acordos que possam atender e minimizar as trágicas consequências. As organizações de modo geral, por sua vez, podem aproveitar o momento, embora difícil, para buscar como uma das estratégias o desenvolvimento de programas de treinamento. Vale lembrar que, ao voltar à normalidade das situações, as organizações que estiverem com seus colaboradores mais bem preparados terão maior possibilidade de se manter e se tornar competitivas no mercado.

Com tais mudanças, com a fragilidade que as organizações têm passado e como se sabe que tudo passa num cenário em que tudo se transforma a cada instante, vale 
destacar, conforme Oliveira; Trajano; Araujo (2016), tais mudanças tem tornado o cenário econômico de incertezas enfrentado pelas organizações, desta forma o capital humano passa a ser ainda mais valorizado pelas empresas e em busca de manutenção desse bem as organizações tem cada vez mais se tornado exigente no desenvolvimento de estratégias e retenção de seu capital humano por meio de programas de educação e aprendizagem corporativa.

O mundo do trabalho atual demanda um conjunto de competências em que a aprendizagem continuada tem sido a premissa. Nesse aspecto, sabe-se que a educação a distância, como modalidade, está bem alinhada à realidade do mundo contemporâneo.

Como os cursos em ambiente on-line exigem do aluno a seu processo de aprendizagem, torna-se importante ter curso ou um programa específico para determinado treinamento, a prática esteja centrada no treinando, permitindo o desenvolvimento de sua reflexão e do pensamento crítico, além de toda uma dinâmica pedagógica, que de fáto seja útil para sua aprendizagem (PROVENZANO; WALDHELM 2009).

Este trabalho busca responder seguinte questão: os recursos e estratégias adotadas pelo modelo de ensino na modalidade a distância (EaP) têm sido suficientemente motivacionas para os cursistas/treinandos durante o período de suspensão de atividades empresariais e de distanciannento social? Como possível resposta, espera-se verificar se a Fundação em estudo, quante à saa prática em relação ao processo de e-ledrning, ver atendendo às necessidades dos cursistas no que se refere aos recursos oferecicos e estratégias adotadas que os motivam a continuar o curso, pautada na melhoria contínua do ensino e comprometimento com a aprendizagem significativa. por meio da modalidade e-learning duranto e período de suspensão de atividades empresariais e de distanciamento social.

Tal abordagem se justifica por contribuir com os estudos que envolvem as relações existentes entre cursos e treinąnentos a distância (e-learning), identificação de recursos e estratégias que geram motivação na $\mathrm{EaD}$, diante de uma eventual necessidade de suspensão parcià e tou total das atividades organizacionais e eventual necessidade de distanciamento social, bem como as reflexões de melhorias, visando um modelo de e-learning pautado em recursos e fatores motivacionais para os envolvidos.

\section{E-learning: Conceitos, práticas e características}

$\mathrm{Na}$ medida em que as informações vêm se sobrepondo, uma das grandes vantagens que vem facilitando a manutenção da aprendizagem do indivíduo está nos recursos que a tecnologia dispõe, permitindo que o treinamento seja transformado numa educação gerenciada pelos envolvidos. Nesse enfoque, o ensino passa de presencial para virtual, exigindo das organizações do conhecimento inovação e investimento em criatividade (OLIVEIRA, 2004). 


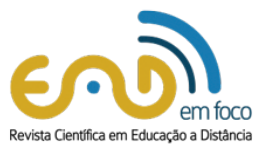

A EaD, como modalidade de educação que possui características que the são próprias e que proporciona grande flexibilidade devido à distância entre educando e educador no espaço e ou tempo, vai ao encontro da visão contemporânea de treinamento e de aprendizagem organizacional, além de desenvolver no treinando a autonomia inerente aos estudantes de cursos em $\mathrm{EaD}$, característica importante no comportamento do trabalhador contemporâneo.

Falar de educação sem incluir no processo de ensino-aprendizagem o uso das tecnologias já não faz sentido; portanto, devemos pensar que a tendência é que a educação seja mediada pelo uso dessas tecnologias e que no futuro próximo a aprendizagem formal não terá mais espaço de tempo e lo

Quando se fala de educação também é preciso educacional, o educando não deve meramente assimilar informações; é muito mais que isso, ou seja, ele deve ter capacidade de assimilar e transfornar essas informacôs em conhecimento. Vale destacar que, ao fazer considerações subre a $\mathrm{EaD}$, não podemos desconsiderar aspectos da modalidade presencial, pois cabe aqui considerar que uma não exclui a outra; devemos considera que ambas têm como fintalidade promover a educação (MARTINS; MILL, 20

Por fazer uso de mídias, impressos e ultimamente o uso de lives etc., recursos de forte propriedade da $\mathrm{EaD}$, os ctursos deven então muito mais que proporcionar assimilação de informaçoes, mas sìn desenvolver a capacidade intelectual do indivíduo, desenvolvendo nele tambemra capacidade de realizar a análise erítica das informações, mudanças de comportamento e transformar informações em conhecimento. Nas palavras de Neloni (2001, apud MARTINS; MILL, 2016), énecessário termos atenção para o uso das tecnologias, as quais-devem atuar no sentido de promover a educação e
não apenas como finalidade informacional. Corroborande com esse pensamento, Monterro, Leite e Barros (2018) destacam a importância de promover as práticas colaborativas em ambientes on-line de aprendizagem, respeitando as especificidades de cada aprendiz e levando em consideração os aspectos relacionados às pessoas e aos processos de formação no processo ensino-aprendizagem. O Quadro 1, elaborado por esses autores, sistematiza alguns dos fatores.

Quadro 1: Aspectos para considerar na formação de adultos em e-learning

\begin{tabular}{|l|l|}
\hline Dimensão & Aspectos \\
\hline \multirow{4}{*}{ Adultos } & Contextos da vida (trabalho, família, social). \\
& Características pessoais (idade, sexo, situação econômica e cultural). \\
& Aprendizagem (necessidades, estilos, background, preocupações, \\
& conhecimento prévio, competências, literacia digital). \\
& Atitudes, motivação e compromisso com a aprendizagem. \\
\hline
\end{tabular}




\begin{tabular}{|l|l|}
\hline \multirow{2}{*}{$\begin{array}{l}\text { E-learning para a } \\
\text { aprendizagem ao }\end{array}$} & $\begin{array}{l}\text { Variáveis tecnológicas (conexão, acesso, suporte, disponibilidade, meio de } \\
\text { comunicação). }\end{array}$ \\
longo da vida & $\begin{array}{l}\text { Aspectos institucionais (gestão, organização, formação de pessoal, } \\
\text { de ensino, abordagens, desenvolvimento curricular, métodos de avaliação, }\end{array}$ \\
& $\begin{array}{l}\text { conteúdos, ambiente virtual de aprendizagem, linguagem, nível de interação). } \\
\text { Confiança (conceito de e-Learning, natureza, segurança, privacidade, } \\
\text { credibilidade, relevância). }\end{array}$ \\
\hline
\end{tabular}

Fonte: MONTEIRO; LEITE; BARROS (2018).

Nesse aspecto, segundo Lemos (2003, apud Ferreira, 2010), o e-learning se sobressai enquanto modalidade de $\mathrm{EaD}$; marcado pelo forte uso de tecnologias, permite eliminar algumas limitações bastante comum na $\mathrm{EaD}$ tais como a falta de interatividade, alto índice de evasão de alunos, conteúdo atrativo e recursos, dentre outros aspectos que atuam como fatores de desafios para os profissionais da área já que a EaD nepr sempre é tão baseada pelo uso da tecnologia.

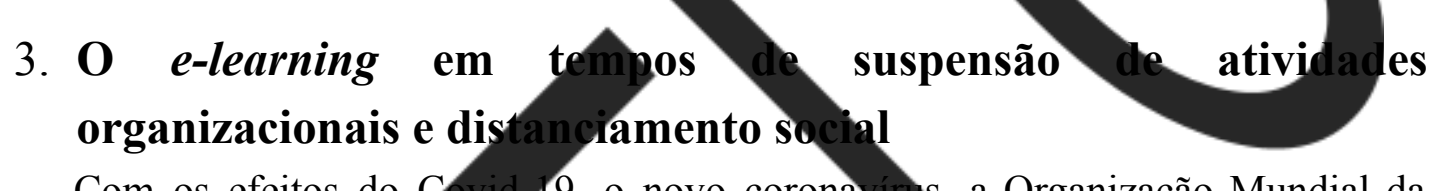

Com os efeitos do Covid 19, o novo coronavirts, a Organizacão Mundial da Saúde (OMS) declarou em 11 de março de 2020 a pandenia.Assim comom boa parte do mundo, no Brasil o coronavírus acabou se disseminando por toco o território e disparando o número decasos de pessoas infectadas. Como medida ce conter a situação, o governo decretou distanciannento social, determinando várias precauções. Com a decisão do Govenno Federal e a livre gestâo dos governos de estados e municípios houve o fechamento de várias atividades de negócios, escolas, instituições religiosas, dentre outras, o que resultou em forte impacto negativo na economia e uma total
mudan a nos hábitos de vida das pessoas (EBC, 2020).

Com a necessidade de adaptar a situação de empregadores e empregados às
determinaçôes tonadas, foi sancionada a Medida Provisória (MP) n 927/20, que permite aos empregadores adaptar as atividades a distância em razão das medidas do distanciamento soctal. A MP, dando liberdade para o empregador adaptar as alterações contratuais conforme seu critério, desde que respeitados os limites estabelecidos na Constituição Federal, permitiu então que muitas atividades alterassem as condições de trabalho do modo presencial para o teletrabalho, trabalho remoto, home office ou outro tipo de trabalho a distância (BRASIL, 2020).

Diante desse cenário, a tecnologia tem sido grande aliada para encurtar o distanciamento, garantir que as atividades continuem em andamento, ou pelo menos parte delas. Um aspecto que se tornou bastante relevante nessa nova rotina das organizações são os treinamentos a distância, o que ajuda não só para aproximar as pessoas, mas também para garantir que o fluxo de trabalho continue (IÁSBECK, 2020).

Quando se fala em e-learning, é necessário pensar nos mais variados recursos tecnológicos necessários para a eficácia de determinado curso e/ou treinamento, assim 
como no uso dessas tecnologias como fonte de aprendizagem, que devem atuar como fonte de interação entre os membros que fazem parte do processo de aprendizagem. Adotar técnicas que fazem uso dos meios para integrar os indivíduos entre si vai permitir não somente a interação por si só, mas a troca de conhecimentos e o desenvolvimento de relações interpessoais, ainda que seja pelo ambiente virtual.

De acordo com Filho; Antunes; Couto (2020), no uso das técnicas empregadas no processo de e-learning é necessário o cuidado de não reduzir o processo de ensino-aprendizagem ao uso dessas técnicas, pois as mídias digitais e a internet por si só não permitem ampliar a capacidade de contato e solução para cada uma das situações reais de aprendizagem cotidianas de cada estudante. As situações reais concretas cabíveis a cada pessoa aparecem subitamente na medida m que ocorro o processo de ensino-aprendizagem e na relação entre os envolvidos; e e nesse contato diceto com a figura que representa o professor que tais situações podem ser compręendidas, analisadas e solucionadas.

Os benefícios do e-learning são vários: vão desde baixos custos em treinamentos até a possibilidade de acompanhar mals de perto o desempenho do colaborador A circunstância que estamos vivendo serve como a oportunidade de entender o potencial que algumas soluções tecnológicas possuem e que auxiliam em políticas de gestão de pessoas, visando implementar a capacitação contínua criando am ambiente de aproximação e de troea mútua entre todos que fazem parte do ambiente corporativo (IÁSBECK, 2020)
Devido as normas restritivas, as empresas buscaram a tecnologia como alternativa para continuar pelo menos parte de stras atividades, pois por meio dela estão conseguindo atender à necessidade do trabalho remoto; com isso, além das atividades que fazem parte do conjunto de tarefas laborais dos colaboradores, foi uma oportunidade que as organizaços tiveram paradesenvolver programas de cursos on-line de capacitação e treinamento. Apesar de algumas dificuldades enfrentadas, viram-se as oportunidades de capacitação e treinamento ajudando os colaboradores tanto no processo de criação quanto de inovaçã̀

O momento de experiência tem feito do treinamento e da capacitação ferramentas estratégicas no desenvolvimento organizacional durante a pandemia. Dessa forma, é uma oportunidade que as corporações vêm experimentando, com a expectativa de, ao passar esse momènto turbulento, que seus colaboradores estejam ainda mais preparados para lidar com novos obstáculos e dificuldades (FREITAS et al., 2020).

\section{Metodologia}

Com a perspectiva de alcançar os objetivos gerais, a pesquisa se caracteriza como exploratória, que segundo Siqueira (2013), este tipo de pesquisa representa a primeira fase de uma pesquisa, com característica bastante flexível, por meio de uso de bibliografias e análise de modelos que proporcione a compreensão do assunto em estudo. 


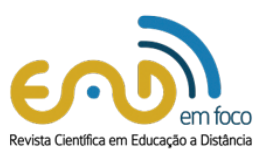

Do ponto de vista da abordagem do problema, este estudo tem como abordagem inicial a pesquisa qualitativa, no entanto, considerando a necessidade da mensuração de alguns dados, num outro momento a pesquisa também terá abordagem quantitativa, como explica Leal e Lima (2009, p. 145): "grande parte das pesquisas qualitativas utiliza também procedimentos quantitativos de tratamento e/ou de análise de dados".

A pesquisa foi realizada em parceria com uma Fundação de ensino superior e especializada em cursos na modalidade de educação a distância, localizada no Estado do Rio de Janeiro. Para tanto, tem como universo cursistas dos cursos de atualização (Formação continuada de professores) e de formação inicial e continuada (Profissionalizante), com o total de 93 participantes. O universo ou população "é um conjunto de elementos que possuem determinadas características; a amostra é vista como cada unidade que compõe a população ou universo (RICHARDSON, 2012, p. 157-158).

Foi utilizado como instrumento araplicação de questionários para cursistas (Apêndice 1), respeitando os princípios éticos com uso do Termo de Consentimento e Livre Esclarecido (TCLE) por meio de aceite eletronico pelos participantes.

O questionário foi estruturadoem duas seções a primeira destinada à coleta de informações sobre os respodentes, a segunda consta de 14 itens, sendo 12 itens respondidos por meio de uma escala Likert, obedecendo aos seguntes critérios: Concordo totalmente $=6$; Concordo muito -5 ; Concordo pouco $=4$; Discordo pouco $=$ 3; Discordo muito 2; Discordo totalmente 1. Assim, as maiores médias são relativas à maior concordância e as média menores, às menores concordâncias. Os 02 itens finais do questionário tratam das questões abertas, sendo classificadas por perguntas e Para as questões abertas foi utilizada a análișe e a interpretação das respostas, pare tanto, as respostas foran categorizadas, eonforme Franco (2021, p. 12) "a categorização é uma peraçầo de classificação de elementos constitutivos de um conjunto, por diferenciação seguida de um reagrupamento baseado em analogias, a partir de criterios definidos".

Os dados colhidos nos questionários foram tabulados por meio do software SPSS, versão 15.0. Foi adotado como procedimento estatístico o Alfa de Cronbach ${ }^{1}$ com a finalidade de verificar a fidedignidade e a consistência dos questionários. De acordo com Hora; Monteiro; Arica (2010), ainda não há um consenso entre pesquisadores acerca da confiabilidade deste teste, assim como também não existe um valor mínimo definido para considerar a consistência do questionário, mas considera-se na maioria da literatura o valor mínimo aceitável 0,70 .

\section{Análise dos Resultados}

${ }^{1}$ O Alfa de Cronbach é uma medida de confiabilidade e avaliação da consistência interna dos questionários, onde os valores variam de 0 a 1,0; quanto mais próximo de 1 maior a confiabilidade dos indicadores (MATTHIENSEN, 2011). 
A tabela 1 apresenta os dados relativos ao sexo e aponta para de $33,33 \%$ dos participantes são homens e $66,67 \%$ mulheres no total. A maioria dos participantes da pesquisa faz parte de cursos de atualização (formação continuada de professores). Com relação ao gênero, a pesquisa apresenta um maior número de mulheres, uma vez que é observado que essa característica de atuação profissional e de cursos na sua maioria o perfil de interesse se dá pelo sexo feminino.

Quanto à idade, os dados informam que na totalidade 9,68\% tem entre 18 e 25 anos, $27,96 \%$ tem entre 26 e 35 anos, $37,63 \%$ tem entre 36 a 45 anos e $24,73 \%$ tem mais de 45 anos, distribuída entre o sexo conforme demonstra a-tabela 1. Concluiu-se que a maioria dos cursistas que participaram da pesquisa são mulheres e com idade entre 36 a 45 anos.

Tabela 1. Número de alunos respondentes por sexo e idade

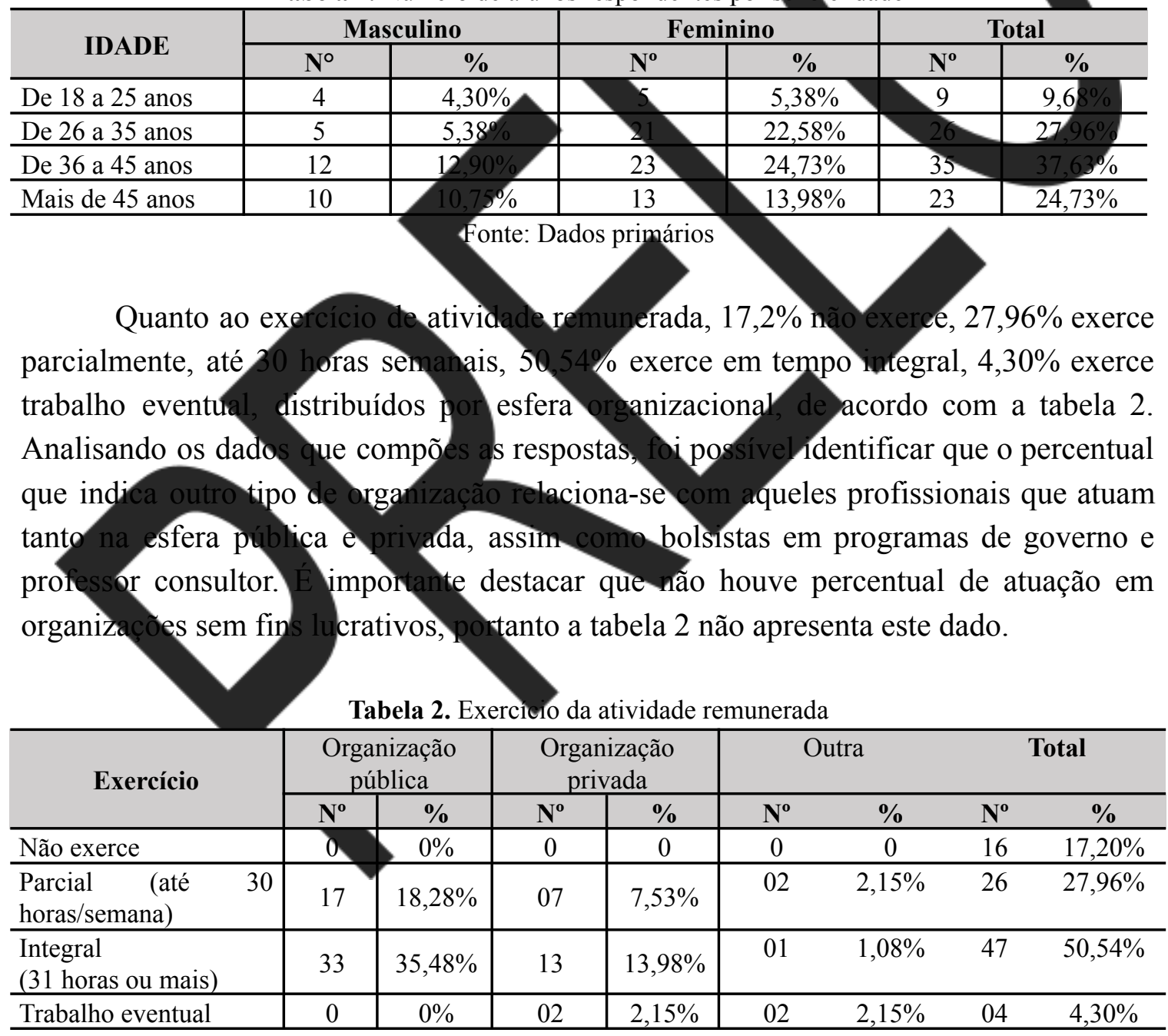

Fonte: Dados primários

O motivo predominante para a escolha do curso se apresenta na tabela 3. Pela análise é possível perceber que a maioria da escolha está relacionada com seu trabalho atual, o que vai de encontro com o objetivo da pesquisa. É possível identificar que o 
percentual de $20 \%$ correspondente ao item oportunidade no mercado de trabalho, está relacionado à amostra do curso de formação inicial e continuada, que por se tratar de um curso que possui uma proposta pedagógica com a finalidade de desenvolver novas aprendizagens para aqueles que estão no mercado de trabalho e preparar aqueles que buscam se inserir ou se recolocar no mercado de trabalho.

Tabela 3. Motivo predominante da escolha do curso

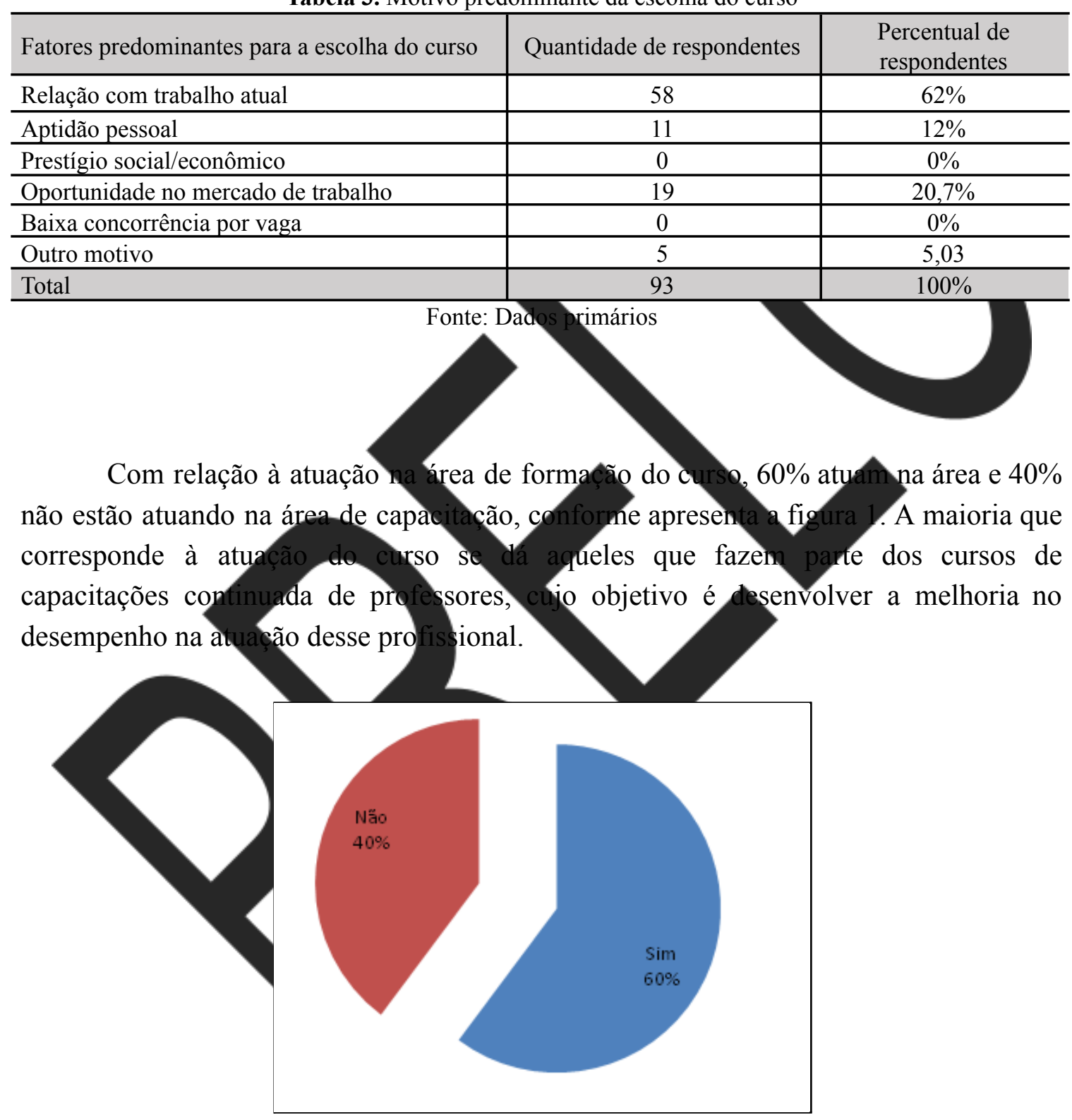

Figura 1. Atuação na área de formação do curso Fonte: Dados primários

Com relação ao meio que utilizam para acessar a sala de aula virtual, 33,60\% pelo computador, $27,20 \%$ pelo celular, $7,20 \%$ pelo tablet, $27,20 \%$ acessam tanto pelo computador, quanto pelo celular e $4,80 \%$ por outros meios, ou seja, fazendo uso de todos esses recursos de acordo com o disponível, conforme figura 2. Conclui-se pela 


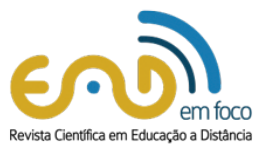

amostra que a maioria daqueles que corresponderam o acesso por meio do celular é participante do curso de formação inicial e continuada.

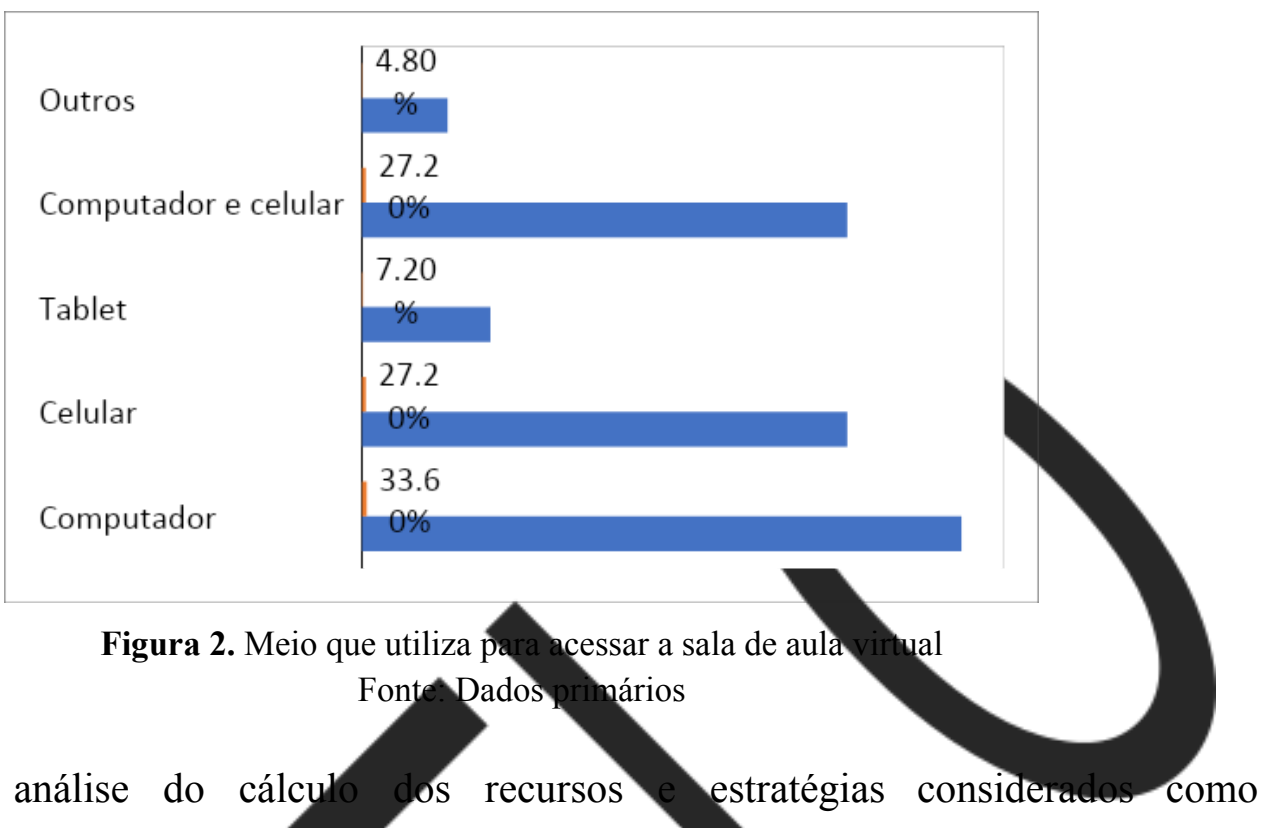

Para análise do cálculo dos recursos e estratégias considerados como motivadores para o cursista/treinando fez um agrupamento de respostas considerando-se as escolhas Discordo totalmente, Discordo muito Concordo pouco, como Tendência a Discordância, assim como as escolhas Discordo pouco, Concorelo totalmente e Concordo muito, como Tendência a concordância, conforme apresenta a tabela 4 .

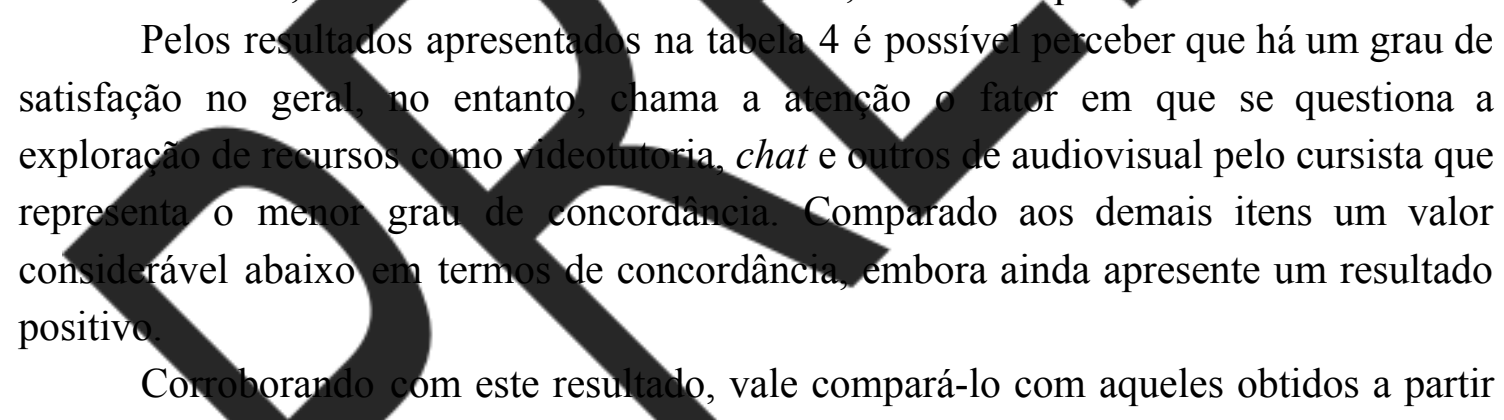
da questão àberta em que discute as mudanças no curso para que o processo de aprendizagem do cursista tenha sido melhor. Foi apresentado a partir das respostas um quantitativo significativo relacionado ao uso de vídeo aulas, assim como o uso de vídeos como suporte no processo de ensino-aprendizagem, o que remete à reflexão do uso de recursos audiovisuais.

Neste aspecto, vale destacar de acordo com Tezolin (2018), a prática de educação a distância torna-se muito mais rica quando se utiliza dos diversos meios para a produção do material de aprendizagem, sobretudo, com o uso dos materiais didáticos audiovisuais.

Chama também atenção o grau de tendência a concordância com relação à atualização do material didático adotado no curso, com $96 \%$.

Uma questão relacionada ao objetivo da pesquisa trata da motivação do cursista com a proposta do curso durante o período de isolamento social, apresentando como 


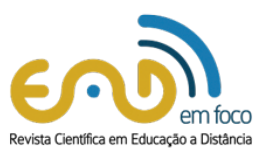

resultados um percentual de tendência a concordância bem significativo, ou seja, $81 \%$ dos respondentes.

Tabela 4. Análise sobre os itens que compõem a satisfação do curso EAD

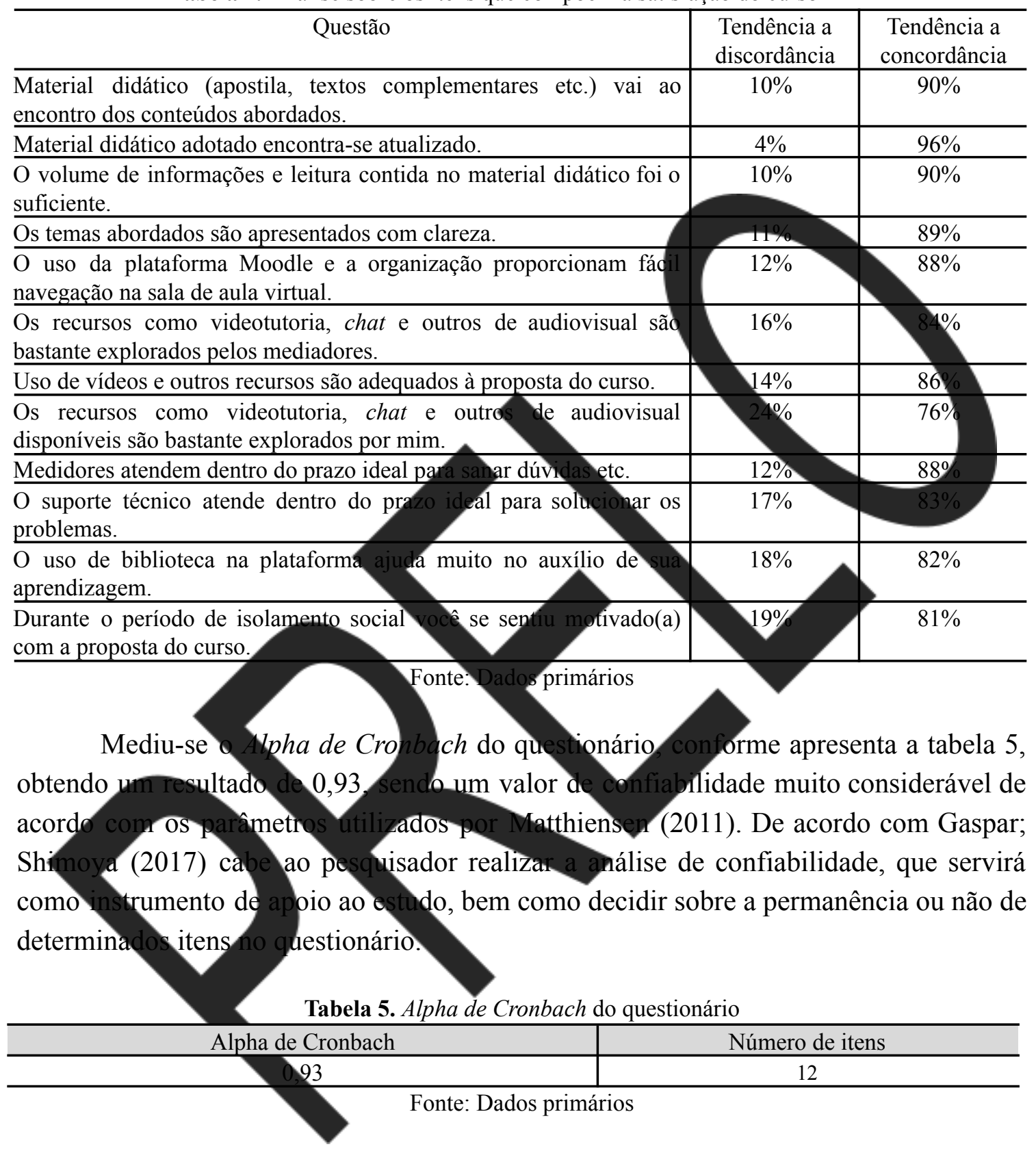

Para a análise das questões abertas dos questionários utilizou-se a análise e interpretação, observando as respostas dos participantes em cada uma das duas questões. De acordo com o mapeamento da pesquisa, busca apresentar algumas colocações mais relevantes e que aparecem com maior frequência nas respostas.

Para a questão que discutia as mudanças no curso para que seu processo de aprendizagem tenha sido melhor, foi possível identificar como representatividade significativa o uso de vídeo aulas, assim como o uso de vídeos como suporte no processo de ensino-aprendizagem. Exemplifica-se de acordo com alguns 
posicionamentos levantados na pesquisa: "Teria vídeoaulas mais explicativas em determinadas matérias". "Poderia ter vídeoaulas". "vídeos aulas", "Presença de vídeotutorias para maior experiência de troca". "Vídeos gravados explicando a matéria". "Que tivéssemos aulas síncronas com os professore e que houvesse outras formas de avaliar sem ser fórum". "Teria vídeoaulas mais explicativas em determinadas matérias". "Poderia ter vídeoaulas". "Um momento de vídeoaula em tempo real". "Mais vídeos com atividades voltados ao ensino fundamental". "vídeos online". "Apresentação em vídeo de algumas atividades". "Colocaria mais vídeo aula ou palestras com grandes especialistas dos temas abordados". "vídeos online". "Colocaria mais vídeos com exemplos de atividades env

A segunda categoria que também houve representatividade significativa relaciona-se com a metodologia e práticas de mediação pedagógica, conforme exemplos: "que as provas não tivessem mais que uma tentativa de resposta (sầo thês). E que houvesse uma recuperação paralelanao final de cada módulo. O módulo que envolve cálculos foi o que mais tive dificuldade, mais exemplos, nesse módulo, poderia ter ajudado". "Referente ao retorno das atividades". "Criação de grupos vid redes sociais para ter mediadores, tutores e colegas mals pertos. Até mesmo conheeer os colegas". "Penso que as atividades poderiam ser propostas de forma mais dinâmica. Muitas vezes o que estava sendo proposto não tinha um exemplo/modelo básico ser seguido. Logo eu nunca sabia se o que pensei para desenvolver stava de acordo. Não me refiro ao fato de fazer um exercicio estilo "copiar-colar" mas penso que a prática antes da atividade avaliada seria o idean". "Metodologid mais ativa, com utilização maior de recursos fora da apostila". "Mais interdtividade entre alunos, turma, professor" "Atguns videos são muito-longos". "Diminui a quantidade de avaliações". "Mudar o modelo dos fóruns, as informaçóes se pevdem". "A mediação precisar ser mais a va. Além disso encontrei pouco entrosamento entre os participantes". "Mais exemplos práticos en laboratôrios próprios de matemática". "Daria mais tempo para o envio das atividades fiquei sem computador no início do curso e não pude enviar algumas tarefas, infelizmente". "O praz das atividades".

A terceira categoria relaciona-se com o material didático, observa-se alguns pontos relevantes a partir das respostas: "Aumentaria mas conteúdo em relação ao Direito Administrativo. "Maior carga horária e apostilas de apoio ao conteúdo". "Colocaria mais apresentações variadas do conteúdo, mais estudos de caso, videoaulas, etc". "Na matéria de tecnologia no curso de Laboratório de Ensino de Matemática: Geometria poderia ter uma apostila básica de Geogebra”. A partir das demais respostas, é possível observar de modo geral satisfação dos cursistas com relação ao curso realizado.

Para a questão que discutia os conhecimentos e habilidades adquiridos pelo curso como utilidade em alguma atividade prática (atividade informal assalariada e/ou trabalho), houve certa diversidade nas respostas, embora seja perceptível que a maioria 
por estar atuando na área de formação do curso, acaba por utilizar de alguma forma esse conhecimento adquirido.

Pode-se exemplificar de acordo com alguns posicionamentos levantados na pesquisa: "Sim, os conhecimentos de Artes me ajudaram a criar atividades para os meus alunos da Educação Infantil." "Sim. Utilizei alguns conceitos na elaboração das minhas aulas." "Com certeza. Tive a oportunidade de aplicar algumas práticas com os alunos nas aulas." "Sim, em meu trabalho, pois por ser minha primeira experiência na área, me ajudou a ter uma base teórica para colocar em prática, já que sou graduada em uma área diferente da que atuo atualmente." "Trabalho informal de revisão de trabalhos acadêmicos." "Me auxiliou nas consultofias a academicos de Artes Plásticas." "Seria utilizado em trabalhos com os alunos do estágio e construção do TCC". "Sim, nas muitas atividades que fiz para meus alunos!" "Sim. Na elaboração de atividades remotas". "Ainda não, mas creio que as utilizarei assim que iniciar meu trabalho em sala de aula." "Sim, várias vezes utilizei as ideias do curso em aulas

Por meio da análise dos dados for possível identificar que o quantitativo que representa aqueles os quais ainda não tyveram a oportunidade de colocar em prática o conhecimento e a aprendizagem ađquinda, são aqueles que ainda não atuarm no mercado de trabalho, na maioria os cursistas do curso de formação inicial e continuada.

\section{Conclusões}

De acordo com objetivo da pesquisa, o presente estudo pão somente apresenta um resultado positivo quanto ao fator motivação, mas foi possível verificar ainda que a Fundação em estudo quanto a sua prática, em relaçáo a sua proposta de ensino e aprendizagem, tem àuado dentro dos pressupostos defendidos pelos autores que discu

Devido à limitação na amostra da pesquáisa, não é possível afirmar que a organização pesquisada de fato atende as necessidades dos cursistas/treinandos no que se refere àrecursos of ecidos, estratégias adotadas e fatores motivacionais para aqueles que estão em processo de e-learning. No entanto, não se pode desconsiderar tal amostra e que a mesma contribui para a percepção de que tal fundação tem se pautado na prática de um modelo em que atende as necessidades do seu público de aprendizagem, assim como em se tratando do fator motivação no período de distanciamento social, as pessoas tem apresentado o interesse em realizar cursos na modalidade a distância.

Vale destacar como recurso fundamental e apontado como uma necessidade por boa parte das pessoas o uso de recursos audiovisuais, ou seja, é necessário considerar que muitas pessoas em processo de aprendizagem ainda necessitam da figura representativa do professor, senão o próprio professor na sala de aula, no caso da $\mathrm{EaD}$, na sala de aula virtual, dada a importância aos recursos audiovisuais.

Pode-se afirmar que o modelo de educação a distância apresentado nesse estudo contribui para identificação de recursos e de estratégias que favoreçam a motivação de cursistas/treinandos, sejam na implantação de novos cursos na própria organização 
pesquisada e/ou como contribuição para outras organizações, no entanto, vale lembrar os pontos que merecem pequenos ajustes para a melhoria, conforme apresentado e discutido nesta pesquisa.

Com este estudo, sugere-se para futuras pesquisas a observância da necessidade de reavaliação da pertinência ou não de determinados itens do questionário.Sugere-se ainda o desenvolvimento de uma pesquisa de campo, por meio de empresas, de forma que os dados levantados permitam a comparação desses resultados, com objetivo de contribuir para o desenvolvimento da $\mathrm{EaD}$ em várias esferas e pautar num modelo de e-learning com qualidade, sobretudo, que seja uma técnica ou-modalidade de ensino que atue como motivadora para os agentes no processo

\section{Referências}
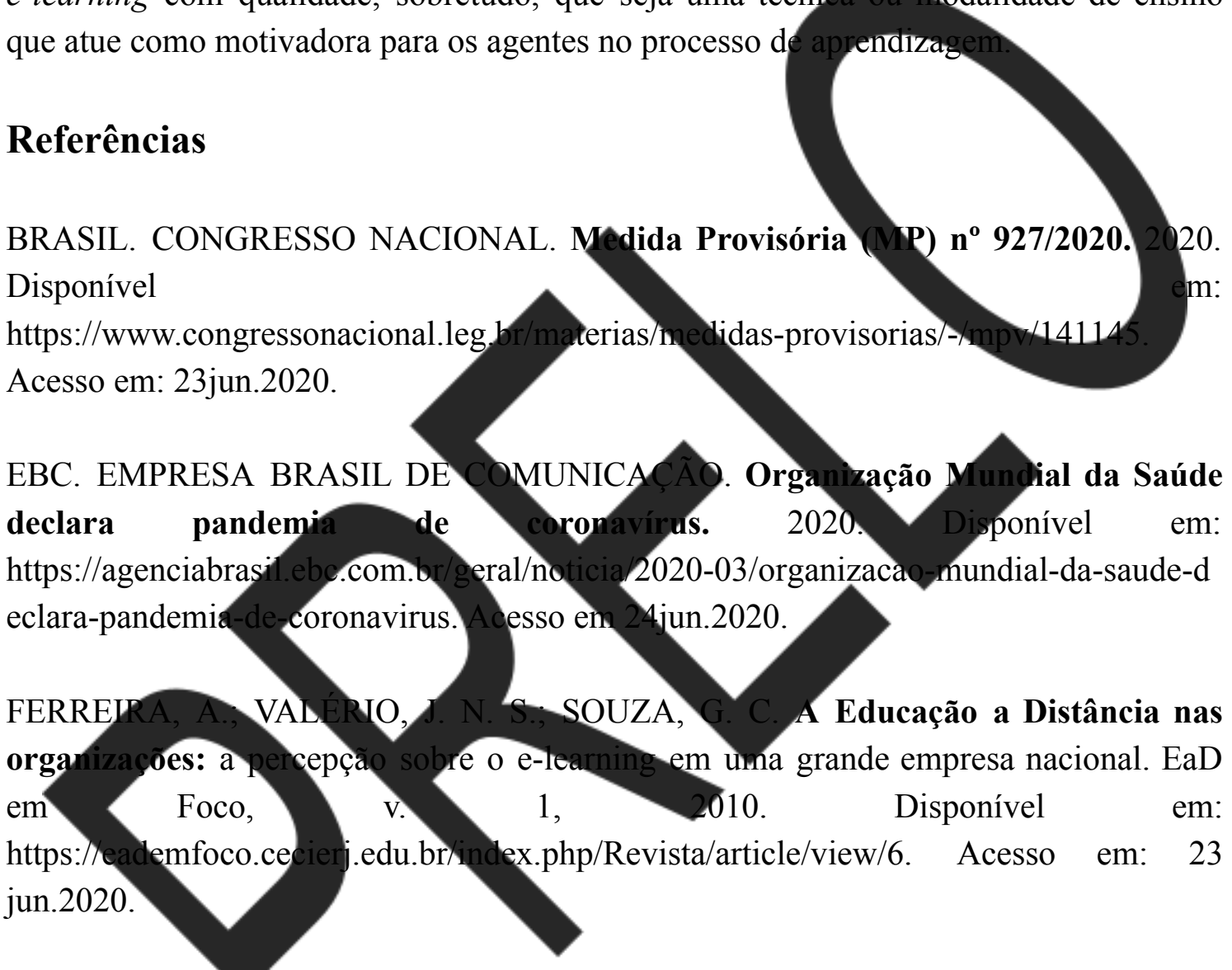

FILHO, A. L. F., ANTUNES, C. F.; COUTO, M. A. C. Alguns apontamentos para uma crítica da edưcação a distância (EaD) na educação brasileira em tempos de pandemia. 2020 Disponível em: https://www.e-publicacoes.uerj.br/index.php/tamoios/article/download/50535/33468. Acesso em: 23jun.2020.

FRANCO, M. L. P. B. Análise de conteúdo [livro eletrônico]. 1.ed. Campinas, SP: Ed. Autores Associados, 2021.

FREITAS, A. R. B. et al. Administração estratégica, gestão de pessoas e Empreendedorismo. In: XI SEMAD - Semana de Administração da Universidade 


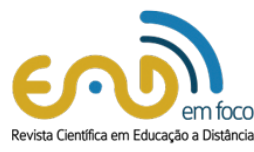

Federal Rural de Pernambuco. Recife/PE, 2020. Anais... Capacitação e treinamento em meio ao cenário pandêmico da Covid-19. Disponível em: http://adm.ufrpe.br/sites/ww4.deinfo.ufrpe.br/files/RESUMO_46.pdf . Acesso em: 25jun.2020.

GASPAR, I. .A.; SHIMOYA, A. Avaliação da confiabilidade de uma pesquisa utilizando 0 coeficiente alfa de cronbach. 2017. Disponível em: https://webcache.googleusercontent.com/search?q=cache:vJTCZkZaItMJ:https://files.ce rcomp.ufg.br/weby/up/1012/o/ISAAC_DE_ABREU_GASPAR_2 email.pdf $+\& c d=3$ $\& \mathrm{hl}=\mathrm{pt}-\mathrm{BR} \& \mathrm{ct}=\mathrm{clnk} \& \mathrm{gl}=$ br. Acesso em: 29.set.2020.

HORA, H. R. M.; MONTEIRO, G. T. R.; ARICA, J. Confiabilidade em Questionários para Qualidade: Um Estudo com o Coeficiente Alfa de Cronbach Produto \& Produção, vol. 11, n. 2, p. 85 - 103, jun. 2010. Disponível en $<$ http://seer.ufrgs.br/index.php/ProdutoProducao/article/view/ 13.ago.2021.

IÁSBECK, S. A importância do treinamento corporativo a distância em tempos de isolamento social 2020 . Disponível em: https://www.hsm.com.br/a-importancia-do-treinamento-corporativo-a-distancia-em-tem pos-de-isolamento-social/. Acesso en: 23 jun.2020. LEAL, M .G. F; LIMA, F. R. Metodologia da pesquisa. Módulo VI, Curso de Especialização em Educação Techologgica. Cefet/RJ. Rio de Janeiro, 2009.

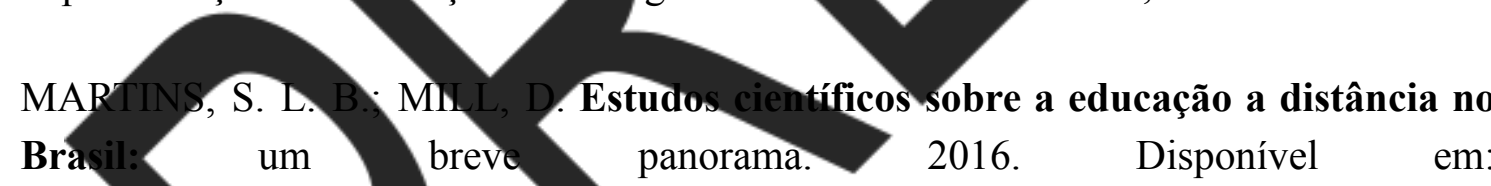
https: $/$ www.google.com/url?sa $=\mathrm{t} \& \mathrm{tct}=\mathrm{j} \& \mathrm{q}=\& \mathrm{esrc}=\mathrm{s} \&$ source $=$ web $\& \mathrm{~cd}=\& \mathrm{cad}=\mathrm{rja} \& u a c t$ $=8 \&$ ved $=\mathbf{2}$ ahUKE iTr DzzqjqAh VCK7kGHZQdBMQQFjAAegQIBBAB\&url=http $\%$ $3 \mathrm{~A} \% 2 \mathrm{~F} \% 2 \mathrm{Frevista}$ ibict.br $\% 2$ Finclusao $\% 2$ Farticle $\% 2 \mathrm{Fdownload} \% 2 \mathrm{~F} 4176 \% 2 \mathrm{~F} 3647 \& \mathrm{u}$ sg=AOvVaw1EUBWQria6-y-ICY-wd_4V. Acesso em: 23jun.2020.

\section{MATTHIENSEN. A. Uso do Coeficiente alfa de cronbach em avaliações por} questionários. 2011. Disponível:

https://www.infoteca.cnptia.embrapa.br/bitstream/doc/936813/1/DOC482011ID112.pdf. Acesso em: 13.ago.2021

MONTEIRO, A.; LEITE, C.; BARROS, R. "Eu ganhei mais o gosto de estudar": o e-learning como um meio de aprendizagem ao longo da vida de reclusas de um estabelecimento prisional português. Educ. Soc., Campinas, v. 39, n. 142, p.129-150,jan./mar.2018. Disponível

em: 


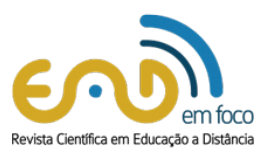

https://www.scielo.br/scielo.php?pid=S0101-73302018000100129\&script=sci_abstract $\&$ tlng=pt. Acesso em: 24 jun.2020.

OLIVEIRA, F. B. Educação corporativa: desenvolvendo e gerenciando competências. São Paulo: Pearson Prentice Hall, 2004.

OLIVEIRA, M. A.; TRAJANO, E. V.; ARAUJO, E. A. S. Capital humano como fator de competitividade e desenvolvimento econômico. R. Científica UBM, Barra Mansa, ano XXI, v. 18, n. 35, p. 151-170, $2^{\circ}$ sem. 2016.

PROVENZANO, M. E.; WALDHELM, M. C. V. Educação tecnológica: didática, módulo IV. Rio de Janeiro: Cefet/RJ, 2009.

RICHARDSON, R. J. et al. Pesquisa social: métodos e técnicas. $3^{\text {a }}$ ed. São Paulo: Atlas, 2012.

SIQUEIRA, M. A. S. Monografias e teses: das normas técnicas ao projetode pesquisa. $2^{\mathrm{a}}$ ed. Brasília: Consulex, 201

TEZOLIN, C. R. C. Ead: A Práticà Pocente na Produção de Materiais Audiovisuais. Revista Aprendizagem em EAD - Ano 2018 - Volume 8 Taguatinga - DF Setembro/2018 Disponível em https://portalrevistas.ucb.br/index.php/raead. Acesso em: 29.set.2020.

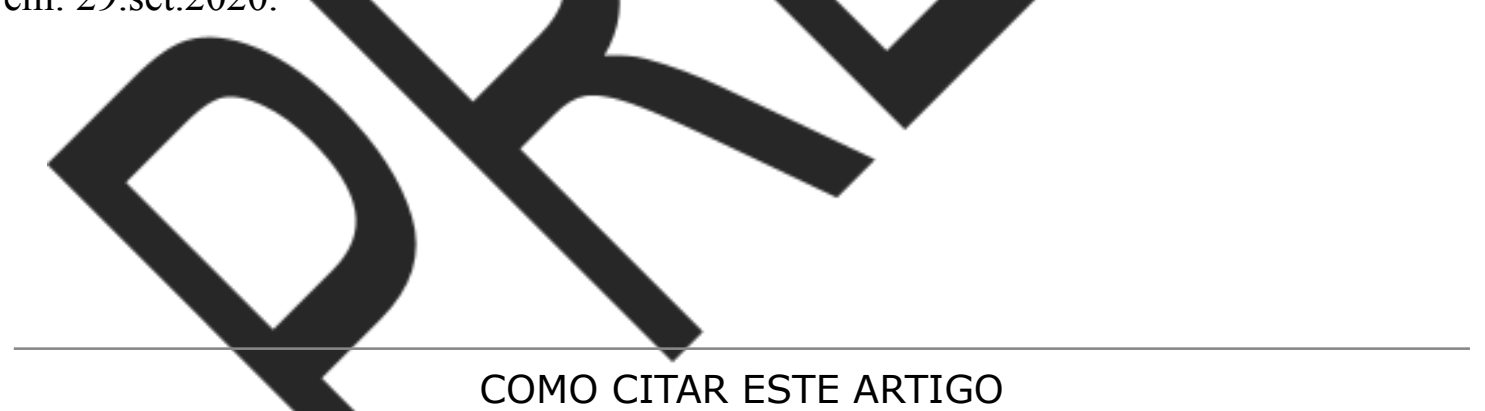

ABNT: OLIVEIRA, M. A. DE; VASQUES, L. V. A Percepção Sobre o E-learning em Períodos de Suspensão das Atividades Organizacionais e de Distanciamento Social, EaD em Foco, v. 11, n. 1, e1485, 2021. doi: https://doi.org/10.18264/eadf.v11i1.1485 